\title{
Further Observations on Meloidogyne indica Whitehead, 1968 from India
}

\author{
Matiyar Rahaman Khan ${ }^{1, *}$, Sabayasachi Pal' ${ }^{2}$ Amit Singh², \\ Ashok Dhananjaybhai Patel ${ }^{3}$, Bhagubhai Ambaram Patel ${ }^{3}$, \\ Tushar Manohar Ghule ${ }^{2}$ and Victor Phani ${ }^{1}$ \\ ${ }^{1}$ Division of Nematology, Indian Agricultural Research Institute, Delhi, India \\ ${ }^{2}$ Department of Agricultural Entomology, Bidhan Chandra Krishi Viswavidyalaya, \\ Kalyani, Nadia, West Bengal, India \\ ${ }^{3}$ Department of Nematology, Anand Agricultural University, Anand, Gujarat, India
}
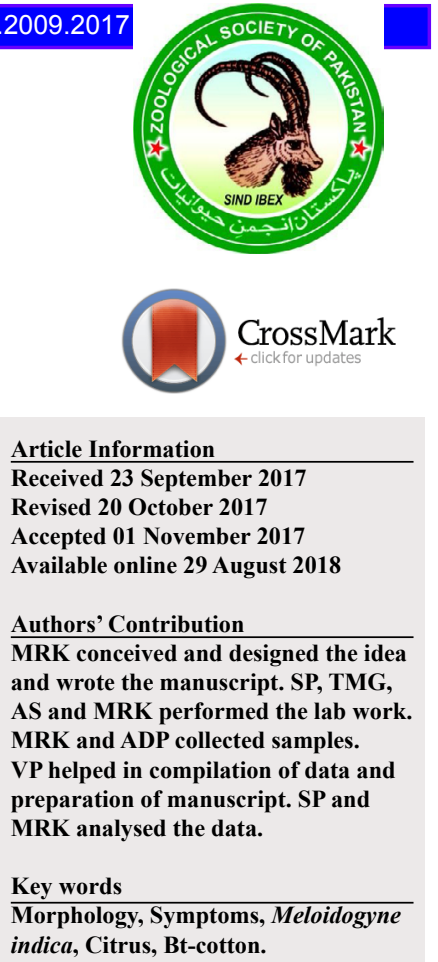

\section{INTRODUCTION}

$C$ Yitrus spp. (family Rutaceae) is one of the most preferred fruits all over the world known for its flavor, rich source of vitamin $\mathrm{C}$, minerals and dietary fiber (non-starch polysaccharides) that are essential for normal growth and development. Several root-knot nematodes have been reported to parasitize citrus in Asian countries, viz., Meloidogyne citri, M. donghaiensis, M. fujianensis, M. mingnanica, $M$. jianyangensis, $M$. kongi, $M$. incognita and $M$. indica (Davis and Venette, 2004). In India, Gujarat state shares about $4.0 \%$ of total citrus production of the country (Anonymous, 2014) and two most popular cultivars viz., Ranpur lime and kagzi lime are grown widely in the state. The occurrence of $M$. indica on kagzi lime (Citrus aurantifolia) was reported from north Gujarat (Patel et al., 1999). The citrus orchards were found to have a severe infestation of root-knot nematodes. Bt-cotton is becoming popular among the conventional citrus growers and the popular crop sequences in Gujarat are cotton (summer)mustard/wheat (winter) or castor (winter)-cotton (summer). Bt-cotton, in this part of country, was also found to have problems of root-knot nematode infestation. Preliminary observation on the root-knot nematode infecting citrus and Bt-cotton (Khan et al., 2014) revealed resemblance to Meloidogyne indica Whitehead, 1968, first time reported

\footnotetext{
Corresponding author: drmrkhanbckv@gmail.com 0030-9923/2018/0006-2009 \$ 9.00/0
}

Copyright 2018 Zoological Society of Pakistan and described on citrus from Delhi, India (Whitehead, 1968). Since description, $M$. indica is not known much from India and it was not further characterized from elsewhere. Currently the information available on $M$. indica is thought inadequate for better understanding the species. Therefore, the present study was focused on further characterization of the species based on morphological, morphometric and biochemical information.

\section{MATERIALS AND METHODS}

Nematode populations and processing of samples

Samples of nematode infested roots of citrus (Citrus aurantifolia cv. kagzi lime) and Bt-cotton plants along with rhizospheric soil of the infested plants were collected from Kharva village of Mehsana district, Gujarat, India; located at N23 $31^{\prime} 70^{\prime \prime}$ and E72 $27^{\prime} 63^{\prime \prime}$. The fields of Btcotton were in fact previously infested with root knot nematodes in citrus. Other crops like castor, Capsicum sp. and brinjal were also sampled. The soil type in the sampled areas is primarily sandy to sandy loam with neutral $\mathrm{pH}$ (6.5-7.5); soil organic carbon is medium with low phosphorus and high potassium. The weather conditions are primarily characterized by extreme summer (March to June) when the temperature goes up to $46^{\circ} \mathrm{C}$, and cool winter (November to February) when it is as low as $9^{\circ} \mathrm{C}$, with total annual rainfall about $800-900 \mathrm{~mm}$.

The root samples were stained by $\mathrm{NaOCl}$-acid fuchsin method (Byrd et al., 1983) and a part of the collected root samples were cut into small pieces for extraction of second 
stage juveniles (J2s) and males by modified Baermann's technique (Whitehead and Hemming, 1965). Extraction of J2s and males from soil was also pursued by the same technique. Egg masses of root-knot nematodes were collected with the help of forceps from the stained root sample and eggs from egg masses were released by teasing them on a glass slide with a needle under stereozoom trinocular microscope (Carl Zeiss: Stemi 2000 C) at 40X magnification.

\section{Host test}

Nematode infested roots and soil from citrus field was mixed with sterile soil and distributed in 10 earthen pots (10 cm dia). At least three pots for each crop were planted with three week-old seedlings of tomato (cv Rutgers), brinjal (cv local), and citrus (kazgi lime, cv local). An additional pot with sterile soil was maintained for each crop as control check. Sixty days after planting, individual plant was uprooted and observed for nematode infection and reproduction.

\section{Morphological and biochemical studies}

Nematode specimens for morphological observations were killed by hot-water bath, then fixed in $4 \%$ formalin solution and stored with proper labeling. Subsequently the specimens were processed by glycerol-ethanol method (Seinhorst, 1959) for light microscopic studies. The processed specimens were then mounted in anhydrous glycerine on glass slides. The morphological characters for Meloidogyne as described by Jepson (1987) and Karssen (2002) were included for in depth identification and characterization of the species. The de-Man ratios and other values were determined from measurements taken with the help of an ocular micrometer (Hooper, 1986). Photomicrographs of males, females and juveniles were taken with a Color Digital Camera (Cannon Power Shot, 20IS) attached to a compound microscope (ZEISSAXIOSKOP 40, Germany). The beta-esterase phenotype of the nematode population was analyzed as per protocol of Esbenshade and Triantaphyllou (1985) and its modification (Khan et al., 2017).

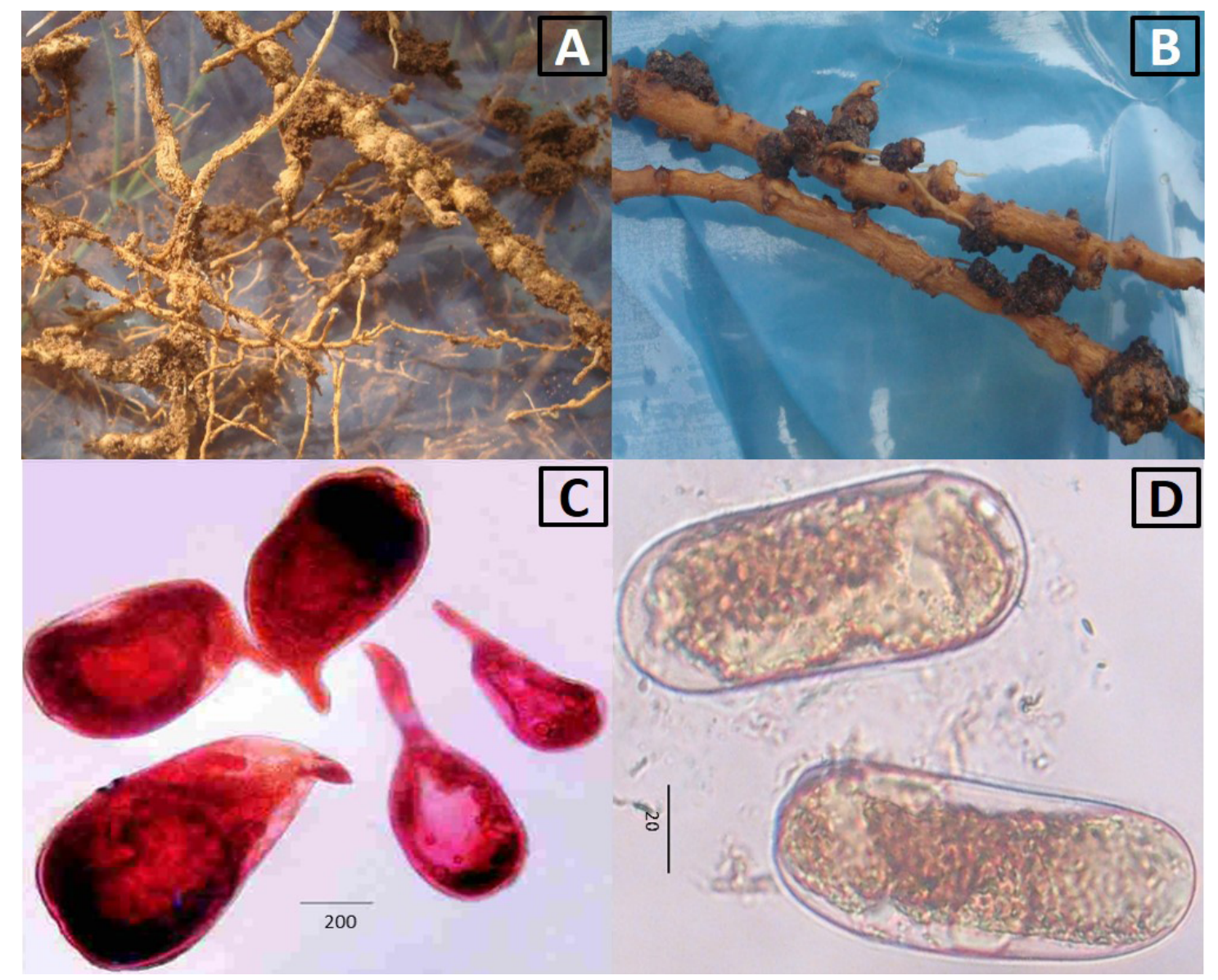

Fig. 1. Symptoms (A, B) induced by Meloidogyne indica in different hosts. Galls on Citrus root (A), Bt-cotton root (B), Adult female (C) and Egg (D). Scale -bar in $\mu \mathrm{m}$. 


\section{RESULTS}

\section{Diagnostic symptoms and identification}

Citrus root-knot nematode ( $M$. indica) is on firm footing on citrus and Bt-cotton growing areas of Mehsana district of Gujarat, India. Nematode infected citrus plants exhibited symptoms almost similar to dieback or decline of older plants. The citrus plants typically exhibited sick appearance, yellowing of leaves, drying of twigs and yielding no fruits. Each plant (age 3-5 year-old) with such symptoms confirmed the infestation of root knot nematode. Inspection of citrus along with castor, capsicum, brinjal grown on adjoining fields revealed occurrence of $M$. indica infestation on citrus (Fig. 1A) only. The castor crop grown in the nearby field showed no infection of root-knot nematodes. However, galled root of brinjal and capsicum showed the presence of M. incognita (Kofoid and White)
Chitwood, 1949. Bt-cotton plants were found to be badly damaged by the infestation (Fig. 1B) of $M$. indica.

The observation on crop hosts viz., tomato (cv Rutgers), brinjal (cv local), and citrus (kazgi lime, cv local) grown on the root-knot nematode-infested soil, after three months (January-March, 2011) revealed infection of $M$. incognita on tomato and brinjal, while citrus root showed typical infestation of $M$. indica. The identification of species of Meloidogyne was confirmed based on morphological observations and beta-esterase phenotyping analysis.

\section{Morphology and morphometrics of $\mathrm{M}$. indica}

The detailed morphology of adult female, male and second stage juvenile of $M$. indica infecting Citrus and Bt-cotton and their morphometrics were studied for characterization and confirmation of species.

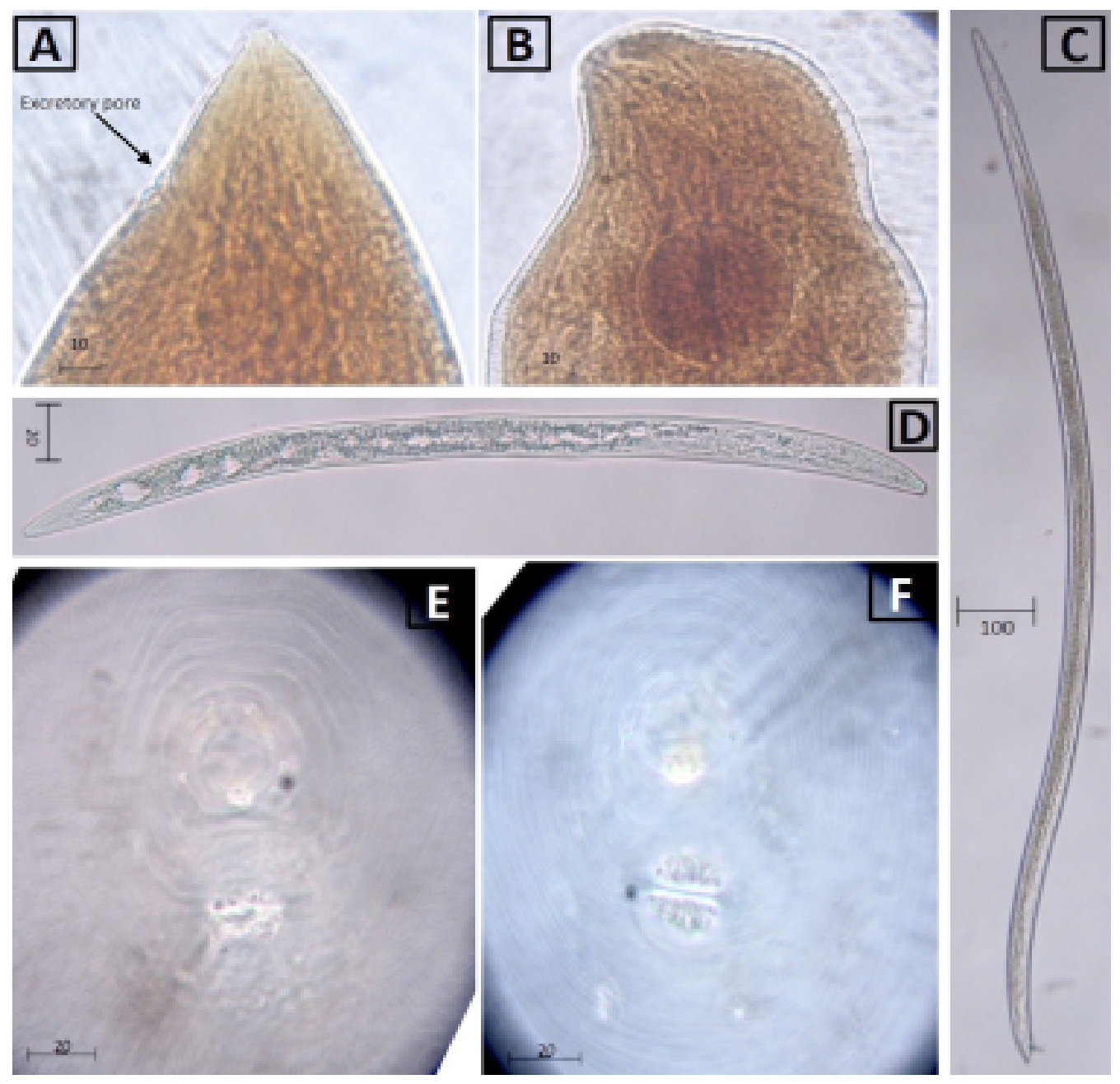

Fig. 2. Meloidogyne indica. A and B, Variations in female head; C, Second stage juvenile; D, Adult male; Perineal pattern: Mehsana (citrus) population (E); Mehsana (Bt-cotton) population (F). Scale -bar in $\mu \mathrm{m}$. 

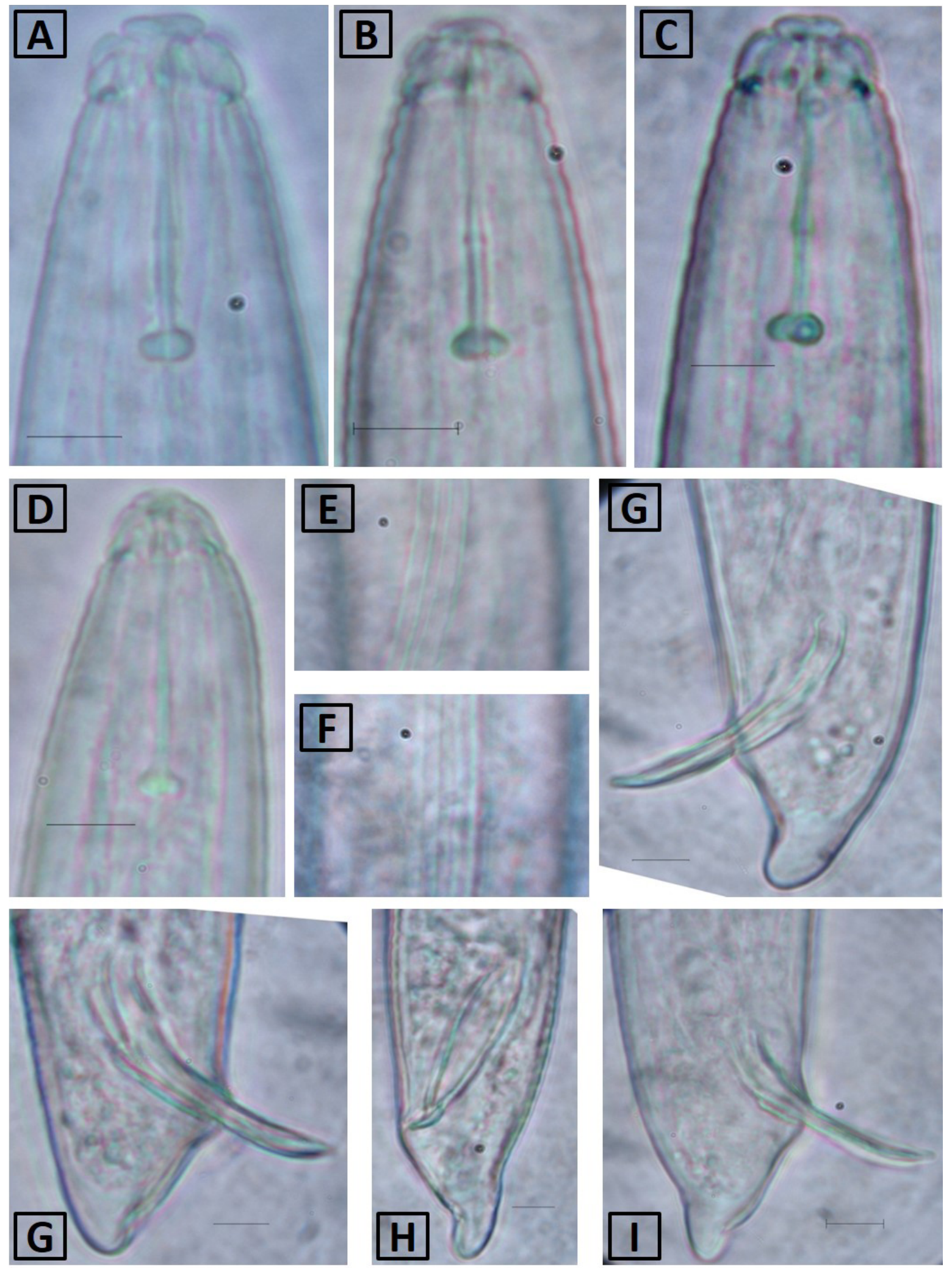

Fig. 3. Variations in anterior end (A-D), posterior end (G-J) and lateral field (E and F) of male. Scale - bar $=5 \mu \mathrm{m}$. 

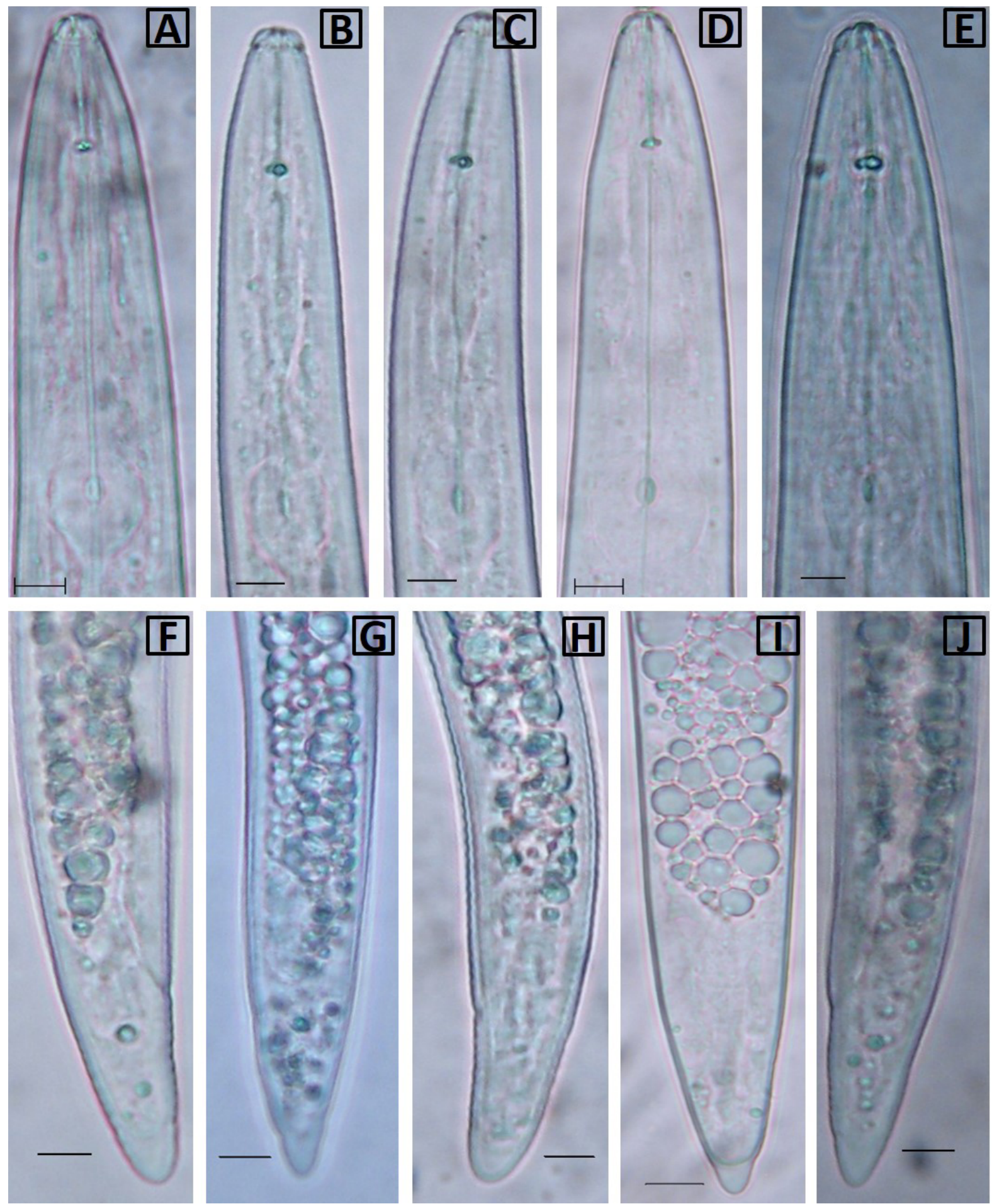

Fig. 4. Variations in anterior end (A-E) and posterior end (F-J) of second stage juveniles. Scale - bar $=5 \mu \mathrm{m}$.

General morphology of M. indica

Female

The body shape appeared pyroid and thick cuticle with considerable variations in shape and size of the $M$. indica (Fig. 1C). Female with short neck (Fig. 2A, B) with six lips. Posterior part of female generally showed smooth 
with protuberance in some specimens. Stylet cone slightly curved dorsally, tapered gradually towards the tip and broadening at the junction with the shaft. Style shaft was cylindrical and broad near the base. Stylet knobs appear transversely ovoid and set off from the shaft. The body dimension showed moderate to high variability $(\mathrm{CV}<20$ to $>20$ ). Mean length of stylet, stylet cone, stylet shaft, length and width of knobs, DGO, length and width of median bulb, length and width of median bulb valve showed little variations. Head to SE-pore showed high variability (CV 28.02).

\section{Perineal pattern}

The perineal pattern is rounded with rounded dorsal arch (Fig. 2E, F). Lateral field without lateral line or any forking in the striae. Striae were very smooth, continuous and striae forming a distinct tail whorl. Both phasmid and anus were distinct and clearly visible. Morphometric parameters of perineal pattern exhibited moderate variations $(\mathrm{CV}<20)$.

\section{Male}

The body dimension of male was relatively smaller (Fig. 2C) as compared to M. incognita. Head not set off, with two annuli behind head cap. Stylet comparatively thin, stylet cone tip pointed and slightly curved. Stylet knobs slightly set off from shaft with backwardly sloping. Lateral lines 5-6. Tail short conoid with terminal portion narrow with smooth end. The morphometric characters viz., body length, body width, stylet length, stylet cone, stylet shaft, length and width of stylet knobs, DGO, head to metacorpus distance, head to SE-pore position and spicule length showed little difference between two populations (Fig. 3).

\section{Second stage juvenile}

The dimension of $\mathrm{J} 2$ showed little difference between the populations. Head not set off and head cap slightly outer. Stylet long and knobs rounded to ovoid. Lateral lines four. Length of tail short (Fig. 2D) and hyaline tail terminus very short (Fig. 4), and rectum not inflated. The mean a-, b'-, b'-, c-, c'-values and mean hyaline tail terminus in both population were almost same.

\section{Egg}

Eggs were comparatively long (Fig. 1D); length, width and their ratio varied considerably.

The comparative morphometric analyses of Mehsana (citrus and Bt-cotton) populations of $M$. indica, along with original measurements of Whitehead (1968) from Delhi on citrus is presented in Table I.

\section{Isozyme pattern}

The isozyme electrophoretic analysis of young egg laying females of $M$. indica (Mehsana population) was carried out, but despite several attempts the esterase enzyme activity of $M$. indica could not be detected (Fig. 5). Specific esterase phenotypes from other root-knot nematodes, $M$. incognita and $M$. javanica were clearly observed. This result helped to differentiate $M$. indica from common species by the esterase phenotype.

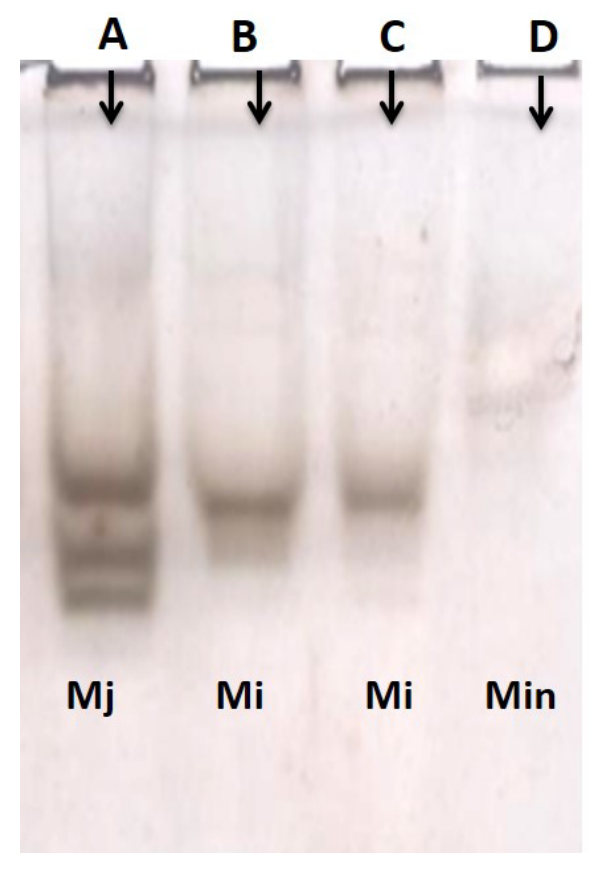

Fig. 5. Beta-esterase phenotypes of Meloidogyne species: A, M. javanica (as standard); B and C, M. incognita; D, M. indica.

\section{DISCUSSION}

Citrus root-knot nematode ( $M$. indica) has been documented in literature as a pest of quarantine significance for its limited distribution in India (Whitehead, 1968; Patel et al., 1999) and in Fujian Province, Wuping of China (Davis and Venette, 2004). The nematode species is known to infect and reproduce on different citrus spp. (Whitehead, 1968; Franklin, 1978; Vovlas and Inserra, 1996, 2000) and morinda (Morinda officianalis) (Zhang and Weng, 1991). However, not much information has been generated on diagnostic symptoms, identity of the species, and its host status. The present investigation identified the field infestation of $M$. indica on Citrus and Bt-cotton grown in the fields which was previously infested with $M$. indica. Thus, $M$. indica is now distributed in the states of Delhi and Gujarat of India. 
Table I.- Comparative morphometric analysis of $M$. indica from citrus and Bt-cotton with Whitehead's citrus population.

\begin{tabular}{|c|c|c|c|}
\hline Characters & $\begin{array}{c}\text { Mehsana population } \\
\text { (Bt-cotton) }\end{array}$ & $\begin{array}{c}\text { Mehsana population } \\
\text { (citrus) }\end{array}$ & $\begin{array}{c}\text { Delhi population (citrus) } \\
\text { (Whitehead, 1968) }\end{array}$ \\
\hline \multicolumn{4}{|l|}{ Male } \\
\hline Body length & $1140 \mu \mathrm{m} \pm 171.43(820-1400)$ & $1266 \mu \mathrm{m} \pm 99.15(1130-1400)$ & -- \\
\hline Body width & $25.98 \mu \mathrm{m} \pm 3.07(20.90-31.35)$ & $31.73 \mu \mathrm{m} \pm 4.28(26.60-35.15)$ & -- \\
\hline $\mathrm{a}$ & $44.10 \pm 6.17(34.21-55.84)$ & $40.47 \pm 5.95(32.15-46.62)$ & -- \\
\hline Stylet length & $16.58 \mu \mathrm{m} \pm 0.57(16.15-18.05)$ & $16.44 \mu \mathrm{m} \pm 0.64(15.68-17.10)$ & -- \\
\hline Stylet cone & $9.71 \mu \mathrm{m} \pm 0.39(9.50-10.45)$ & $9.31 \mu \mathrm{m} \pm 0.26(9.03-9.50)$ & -- \\
\hline Stylet shaft & $5.11 \mu \mathrm{m} \pm 0.37(4.75-5.10)$ & $5.32 \mu \mathrm{m} \pm 0.40(4.75-5.70)$ & -- \\
\hline Knobs height & $1.76 \mu \mathrm{m} \pm 0.22(1.43-1.90)$ & $1.81 \mu \mathrm{m} \pm 0.21(1.43-1.90)$ & -- \\
\hline Knobs width & $3.04 \mu \pm 0.47(1.90-3.80)$ & $2.95 \mu \mathrm{m} \pm 0.21(2.85-3.33)$ & -- \\
\hline DGO & $3.25 \mu \mathrm{m} \pm 0.44(2.85-3.80)$ & $3.61 \mu \mathrm{m} \pm 0.54(2.85-4.28)$ & -- \\
\hline Head-metacorpus & $70.73 \mu \mathrm{m} \pm 5.55(58.90-78.85)$ & $76.38 \mu \mathrm{m} \pm 7.28(65.55-82.65)$ & -- \\
\hline b" & $16.16 \pm 2.39(11.51-20.71)$ & $16.69 \pm 1.94(13.67-18.92)$ & -- \\
\hline Head-SE pore & $108.25 \mu \mathrm{m} \pm 14.41(81.70-130.15)$ & $111.91 \mu \mathrm{m} \pm 16.58(87.40-126.35)$ & -- \\
\hline Spicule & $25.79 \mu \mathrm{m} \pm 2.51(21.85-31.35)$ & $27.36 \mu \mathrm{m} \pm 1.24(25.65-28.50)$ & -- \\
\hline \multicolumn{4}{|l|}{ Second stage juvenile } \\
\hline Body length & $462.75 \mu \mathrm{m} \pm 32.46(400-535)$ & $474.25 \mu \mathrm{m} \pm 41.81(390-525)$ & $414 \mu \mathrm{m} \pm 4.5(381-448)$ \\
\hline Body width & $17.10 \mu \mathrm{m} \pm 2.97(13.30-21.85)$ & $18.38 \mu \mathrm{m} \pm 2.23(15.20-21.85)$ & -- \\
\hline Stylet length & $13.21 \mu \mathrm{m} \pm 0.61(12.35-14.25)$ & $12.33 \mu \mathrm{m} \pm 0.33(11.88-13.30)$ & $12 \mu \mathrm{m} \pm 0.9(10-14)$ \\
\hline MB length & $12.45 \mu \mathrm{m} \pm 0.87(11.40-14.25)$ & $11.85 \mu \mathrm{m} \pm 1.11(10.45-14.25)$ & -- \\
\hline MB width & $8.69 \mu \mathrm{m} \pm 0.87(7.60-10.45)$ & $9.17 \mu \mathrm{m} \pm 0.90(8.08-10.93)$ & -- \\
\hline $\mathrm{a}$ & $27.58 \pm 3.51(21.97-34.21)$ & $25.99 \pm 2.40(23.27-30.26)$ & -- \\
\hline$b^{\prime}$ & $3.68 \pm 0.25(3.19-4.19)$ & $3.64 \pm 0.33(3.02-4.13)$ & -- \\
\hline$b^{\prime \prime}$ & $9.10 \pm 0.68(7.80-10.24)$ & $9.34 \pm 1.16(6.73-10.74)$ & -- \\
\hline $\mathrm{c}$ & $24.11 \pm 1.26(21.80-26.61)$ & $35.43 \pm 6.01(25.66-47.37)$ & $24.9 \mu \mathrm{m} \pm 1.36(21.2-31)$ \\
\hline$c^{\prime}$ & $1.83 \pm 0.13(1.54-2.00)$ & $1.45 \pm 0.23(1.05-1.78)$ & $1.57 \mu \mathrm{m} \pm 0.012(1.06-1.78)$ \\
\hline Head-SE pore & $80.94 \mu \mathrm{m} \pm 5.24(73.15-91.20)$ & $79.66 \mu \mathrm{m} \pm 7.30(65.55-92.15)$ & -- \\
\hline DGO & $2.83 \mu \mathrm{m} \pm 0.19(2.38-3.33)$ & $3.02 \mu \mathrm{m} \pm 0.32(2.38-3.80)$ & -- \\
\hline Head-metacorpus & $50.92 \mu \mathrm{m} \pm 1.93(44.65-54.15)$ & $51.16 \mu \mathrm{m} \pm 4.16(47.50-61.75)$ & -- \\
\hline Head-oesophageal gland & $126.11 \mu \mathrm{m} \pm 8.10(114.95-145.35)$ & $130.63 \mu \mathrm{m} \pm 6.62(120.65-142.50)$ & -- \\
\hline Tail length & $19.24 \mu \pm 1.60(17.10-21.85)$ & $13.66 \mu \mathrm{m} \pm 1.87(9.50-16.15)$ & $16.8 \mu \mathrm{m} \pm 1.88(13-20.1)$ \\
\hline Hyaline tail terminus & $4.66 \mu \mathrm{m} \pm 0.40(3.80-5.70)$ & $4.18 \mu \pm 0.63(2.85-5.23)$ & -- \\
\hline Anal body width & $10.55 \mu \pm 0.97(9.5012 .35)$ & $9.52 \mu \mathrm{m} \pm 0.98(8.55-11.40)$ & -- \\
\hline \multicolumn{4}{|l|}{ Female } \\
\hline Body length & $683 \mu \mathrm{m} \pm 138.19(370-900)$ & -- & -- \\
\hline Body width & $418 \mu \mathrm{m} \pm 70.61(300-520)$ & -- & -- \\
\hline a & $1.64 \pm 0.28(1.21-2.23)$ & -- & -- \\
\hline Stylet length & $13.14 \mu \mathrm{m} \pm 0.56(12.35-15.20)$ & -- & $14 \mu \mathrm{m}(12-16)$ \\
\hline Stylet cone & $8.53 \mu \mathrm{m} \pm 0.39(7.60-9.50)$ & -- & -- \\
\hline Stylet shaft & $3.90 \mu \mathrm{m} \pm 0.40(2.85-4.75)$ & -- & -- \\
\hline Knobs height & $1.02 \mu \mathrm{m} \pm 0.17(0.95-1.43)$ & -- & -- \\
\hline Knobs width & $3.80 \mu \mathrm{m} \pm 0.15(3.33-4.28)$ & -- & $5 \mu \mathrm{m}(4-5)$ \\
\hline DGO & $2.92 \mu \mathrm{m} \pm 0.32(2.38-3.80)$ & -- & $3 \mu \mathrm{m}(2-4)$ \\
\hline MB length & $31.02 \mu \mathrm{m} \pm 3.10(25.65-36.10)$ & -- & $38 \mu \mathrm{m}(31-43)$ \\
\hline MB width & $28.60 \mu \mathrm{m} \pm 3.93(23.75-36.10)$ & -- & $39 \mu \mathrm{m}(33-46)$ \\
\hline Length MB valve & $12.59 \mu \mathrm{m} \pm 0.86(11.40-15.20)$ & -- & $14 \mu \mathrm{m}(13-16)$ \\
\hline Width MB valve & $8.41 \mu \mathrm{m} \pm 0.89(6.65-9.50)$ & -- & $9 \mu \mathrm{m}(7-11)$ \\
\hline Head-SE pore distance & $22.71 \mu \mathrm{m} \pm 6.36(14.25-36.10)$ & -- & -- \\
\hline
\end{tabular}




\begin{tabular}{lccc}
\hline Characters & $\begin{array}{c}\text { Mehsana population } \\
\text { (Bt-cotton) }\end{array}$ & $\begin{array}{c}\text { Mehsana population } \\
\text { (citrus) }\end{array}$ & $\begin{array}{c}\text { Delhi population (citrus) } \\
\text { (Whitehead, 1968) }\end{array}$ \\
\hline Egg & $114.75 \mu \mathrm{m} \pm 3.53(110-120)$ & -- & $77 \mu \mathrm{m} \pm 4.70(381-448)$ \\
Length & $44.88 \mu \mathrm{m} 3.58(40-50)$ & -- & $30 \mu \mathrm{m} \pm 1.90(26.35)$ \\
Width & $2.57 \pm 0.20(2.20-2.88)$ & -- & -- \\
Ratio & & -- & -- \\
Perineal pattern & $21.00 \mu \mathrm{m} \pm 2.95(13.30-25.65)$ & -- & -- \\
Vulval slit length & $24.18 \mu \mathrm{m} \pm 3.56(17.10-30.40)$ & -- & -- \\
Inter-phasmid & $21.80 \mu \mathrm{m} \pm 3.56(14.25-27.55)$ & -- & -- \\
Vulva-anus & $31.07 \mu \mathrm{m} \pm 4.04(23.75-38.95)$ & & \\
Vulval slit-tail terminus &
\end{tabular}

Efforts for testing crop hosts viz., tomato (cv Rutgers), brinjal (cv local), and citrus (kazgi lime, cv local) against $M$. indica with the soil infested with the same species, indicated that $M$. indica can infect only citrus, though the soil from both Bt-cotton and citrus rhizosphere are co-inhabited by the $M$. indica and $M$. incognita. None of the citrus and Bt-cotton plants were found infected by M. incognita either in field or pot conditions. The galls produced on the citrus root appeared thick with small eggmass (less than 50 eggs) concealed inside the root. The species was first time reported from Delhi on citrus and further occurrence or interception was not noted earlier from India reveals its limited distribution. Further occurrence of $M$. indica on citrus (cv kagzi lime) and Btcotton from Mehsana district of Gujarat are believed to be the recent report from additional areas of infestation within India. Whitehead (1968) described the species based on limited number of specimens, and adequate morphometric data was not presented. The present study generated detailed morphology and morphometric illustrations of $M$. indica populations from Mehsana (citrus and Bt-cotton). These are in conformity with the description of Whitehead (1968) with slight deviations. The dimension of median bulb in female was smaller in the Bt-cotton of Mehsana population. Body dimension, stylet cone, shaft and other parameters of mature female were not taken into consideration in the previous studies. The length of second stage juvenile, tail length and egg dimensions of $M$. indica were relatively larger than that of Whitehead's Delhi (citrus) population. However, these differences may be considered as intra-specific variation for the species. The second stage juveniles of $M$. indica showed distinctiveness in anterior end as well as posterior end. The tail shape observed as typically short conoid with blunt terminus and smooth and hyaline tail region. Further this study provided differential and supplementary taxonomic characters of male, female, second stage juvenile and eggs. The perineal pattern morphology was typical for species as described by Whitehead (1968). The morphometrics of female from citrus was not included here as sufficient number of specimens was not available for lateral mounting and measurements. However, male and second stage juveniles of $M$. indica were studied for morphometric variations. Morphometrics of male were not studied earlier and, therefore, the data generated here could not be compared with Whitehead's population. In the original description, only three males were available for morphological description, they are in conformity with Bt-cotton and citrus population. However, the number of lateral lines in the lateral fields noted here varied from five to six instead of four in the original description. The tail shape and position of cloaca was almost similar with that of Whitehead's descriptions. The second stage juvenile of $M$. indica showed distinctiveness in anterior as well as posterior ends, tail shape typically short conoid, terminus blunt and smooth, and hyaline tail region. The tail shape and position of cloaca are almost similar with that of Whitehead's descriptions. The scanning electron microscopy (SEM) photomicrograph also showed minute morphological details of male, female and juveniles.

This study provides morphological, morphometric and biochemical information on $M$. indica infecting citrus and Bt-cotton in India. The observation on light microscopy, host tests, beta-esterase enzyme phenotypes are quite relevant to $M$. indica for better understanding of the species described by Whitehead (1968) from India.

\section{ACKNOWLEDGEMENTS}

The authors thank Bidhan Chandra Krishi Viswavidyalaya for support and conducting partial research works at Kalyani Centre. The authors are also grateful to Division of Nematology, ICAR-Indian Agricultural Research Institute, New Delhi for extending facilities to complete the investigation.

Statement of conflict of interest

Authors have declared no conflict of interest. 


\section{REFERENCES}

Anonymous, 2014. Indian horticulture database 2014. National Horticulture Board, India. http://nhb.gov. in/area-pro/NHB_Database_2015.pdf

Altschul, S.F., Gish, W., Miller, W., Myers, E.W. and Lipman, D.J., 1990. Basic local alignment search tool. J. mol. Biol., 215: 403-410. https://doi. org/10.1016/S0022-2836(05)80360-2

Byrd, D.W., Krikpatrick, Jr. T. and Barker, K.R., 1983. An improved technique for clearing and staining plant tissue for detection of nematodes. J. Nematol., 15: 142-143.

Davis, E.E. and Venette, R.C., 2004. Mini risk assessment: Asian Citrus root knot nematodes, Meloidogyne citri Zhang, Gao \& Weng; $M$. donghaiensis Zheng, Lin \& Zheng; M. fujianenesis Pan; $M$. indica Whitehead; $M$. jianyangensis Yang, Hu, Chen \& Zhu; M. kongi Yang, Wang \& Feng; and $M$. mingnanica Zhang [Nematoda: Meloidogynidae]. Cooperative Agricultural Pest Survey, Animal and Plant Health Inspection Service, US Department of Agriculture.

Esbenshade, P.R. and Triantaphyllou, A.C., 1985. Identification of major Meloidogyne species employing enzyme phenotypes as differentiating characters. In: An Advanced Treatise on Meloidogyne. eds. J.N. Sasser, J.N. and C.C. Carter. North Carolina State University Graphics, Raleigh, NC, USA. pp. 135-140.

Franklin, M.T., 1978. Meloidogyne, Plate VII. In: Plant nematology (ed. J.F. Southey). Ministry of Agriculture Fisheries and Food; Her Majesty's Stationery Office (HMSO), London. pp. 98-124.

Hooper, D.J., 1986. Drawing and measuring nematodes. In: Laboratory methods for work with plant and soil nematodes (ed. J.F. Southey). Ministry of Agriculture, Fisheries and Food, London. Reference Book No. 402.

Jepson, S.B., 1987. Identification of root-knot nematodes (Meloidogyne species). CAB International, Wallingford, UK.

Karssen, G., 2002. The plant-parasitic nematode Genus Meloidogyne Goeldi, 1892 (Tylenchida) in Europe. Brill Academic Publishers, Leiden, The
Netherlands

Khan, M.R., Jain, R.K., Ghule, T.M. and Pal, S., 2014. Root knot nematodes in India-A comprehensive monograph. All India Coordinated Research Project on Plant Parasitic nematodes with Integrated approach for their Control, Indian Agricultural Research Institute, New Delhi, pp. 107.

Khan, M.R., Pal, S., Ghule, T.M., Bhattacharyya, S., Singh, A., Sarkar, P. and Lalliansanga, S., 2017. Detection, diagnosis and pathogenic potential of Meloidogyne incognita on passion fruit from Mizoram, India. Pakistan J. Zool., 49: 1207-1214.

Patel, D.J., Patel, B.A., Patel, S.K., Patel, R.L. and Patel, R.G., 1999. Root knot nematode, Meloidogyne indica on kagzi lime in north Gujarat. Indian $J$. Nematol., 29: 197.

Patel, H.R., Patel, R.G., Patel, B.A., Vyas, R.V., Patel, J.G. and Patel, D.J., 2003. Biodiversity of Meloidogyne indica - A key pest of kagzi lime makes castor (Ricinus communis L.) vulnerable. Indian J. Nematol., 33: 174-176.

Seinhorst, J.W., 1959. A rapid method for the transfer of nematodes from fixative to anhydrous glycerin. Nematologica, 15: 67-69. https://doi. org/10.1163/187529259X00381

Vovlas, N. and Inserra, R.N., 1996. Distribution and parasitism of root-knot nematodes on citrus. Nematology Circular No. 217. Florida Department of Agriculture and Consumer Services, Division of Plant Industry, Gainesville, FL, USA.

Vovlas, N. and Inserra, R.N., 2000. Root-knot nematodes as parasites of citrus. Proc. Int. Soc. Citricult., 2: 812-817.

Whitehead, A.G. and Hemming, J.R., 1965. A comparison of some quantitative methods of extracting small vermiform nematodes from soil. Annls. appl. Biol., 55: 25-38.

Whitehead, A.G., 1968. Taxonomy of Meloidogyne (Nematodea: Heteroderidae) with descriptions of four new species. Trans. zool. Soc. London, 31: 263401. https://doi.org/10.1111/j.1096-3642.1968. tb00368.x

Zhang, S.S. and Weng, Z.M., 1991. Identification of root-knot nematode species in Fujian. J. Fujian Agric. College, 20: 158-160. 